\section{THU0641 THE DISEASE BURDEN OF SYSTEMIC JUVENILE IDIOPATHIC ARTHRITIS FOR PATIENTS AND CAREGIVERS: AN INTERNATIONAL HEALTH RELATED QUALITY OF LIFE SURVEY AND RETROSPECTIVE CHART REVIEW}

S. Shenoi ${ }^{1}$, G. Horneff ${ }^{2}$, M. Cidon ${ }^{3}$, A. Ramanan ${ }^{4}$, Y. Kimura ${ }^{5}$, P. Quartier ${ }^{6}$

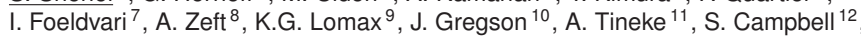
J. Weiss ${ }^{13}$, N. Marinsek ${ }^{12}$, D. Patel ${ }^{12}, N$. Wulffraat ${ }^{14} .{ }^{1}$ Seattle Children's Hospital, Seattle, United States; ${ }^{2}$ Asklepios Kliniken GmbH, Hamburg, Germany; ${ }^{3}$ Stanford University, Palo Alto, United States; ${ }^{4}$ University Hospitals Bristol, Bristol, United Kingdom; ${ }^{5}$ Hackensack University Medical Center, New Jersey, United States; ${ }^{6}$ Paris-Descartes University Necker-Enfants Malades Hospital, Paris, France; ${ }^{7}$ Hamburger Zentrum für Kinder-und Jugend Rheumatologie, Hamburg, Germany; ${ }^{8}$ Pediatrics Rheumatology, Cleveland Clinic, Cleveland; ${ }^{9}$ Novartis Pharmaceutical Corporation, New Jersey, United States; ${ }^{10}$ Novartis Pharma AG, Basel, Switzerland; ${ }^{11}$ VU University Medical Centre, Amsterdam, Netherlands; ${ }^{12}$ Navigant Consulting Inc., London, United Kingdom; ${ }^{13}$ Navigant Consulting Inc., San Francisco, United States; ${ }^{14}$ Wilhelmina Kinderziekenhuis, Utrect, Netherlands

Background: Systemic juvenile idiopathic arthritis (SJIA) is a severe autoinflammatory disease characterised by systemic features including high fevers, rash and arthritis. SJIA can impose a high physical, psychosocial, behavioral and financial burden on patients (pts) and their families.

Objectives: To analyse the impact of the burden of SJIA by evaluating caregiver perspectives of disease burden utilising a SJIA-specific questionnaire combined with physician data about disease severity and treatment in an international, real-world study.

Methods: SJIA treatment centers in France, Germany, Netherlands, UK and the US participated. Pts (aged 4-18 years) with confirmed SJIA received one of the following biologic treatments for $\geq 2$ months: anakinra (ANA), canakinumab (CAN), or tocilizumab (TOC). SJIA burden in patients on biologics was assessed using a caregiver questionnaire and retrospective chart review. Validated measures included: Child Health Questionnaire Parent-Form 50 (CHQ-PF50), 36-Item ShortForm Health Survey (SF-36v2) and Work Productivity and Activity Impairment questionnaire: Specific Health Problem (WPAI:SHP). Caregivers completed function, treatment satisfaction and resource utilization questions.

Results: Sixty-one pts enrolled from June 2015- June 2016: 12 on ANA, 25 on CAN, 24 on TOC; $46 \%$ from the US; $48 \%$ female; mean age at survey was 11.3 years. Mean age at SJIA diagnosis was 6.4 years, mean age at start of ANA, CAN, and TOC treatment was 9.9, 9.1, and 7.5 years, respectively. Caregivers were $79 \%$ female, mean age 41.2 years, and $36 \%$ reduced or stopped working due to their child's SJIA. Of the pts enrolled on CAN and TOC, $72 \%$ and $46 \%$ respectively had previously been on ANA. Baseline CHAQ, CHQ-PF50, and WPAI scores were worse in CAN and TOC than ANA pts. Mean ( \pm SD) CHQ-PF50 physical (PhS) and psychosocial (PsS) summary scores were significantly lower in SJIA patients than a normative population (PhS: $40.0 \pm 18.2$ vs. $53.0 \pm 8.8$; PsS: $46.6 \pm 11.3$ vs. $51.2 \pm 9.1)$ as was caregivers' mean SF-36v2 mental component score $(46.2 \pm 10.7$ vs. $50.0+10)$. Highest caregiver stressors were worry over long-term SJIA impact on their child $(45 \%)$ and uncertainty about the future $(28 \%)$.

Conclusions: Treatment sequencing and patient-reported outcome measures indicate ANA is used as 1 st line for less severe SJIA while CAN and TOC are used as $2 n d / 3 r d$ line for severe SJIA. Caregivers expressed stress over the long-term impact of SJIA and fear for the future and had variable treatment satisfaction and resource utilisation levels.

Disclosure of Interest: S. Shenoi: None declared, G. Horneff Grant/research support from: Abbvie, Chugai, Novartis, Pfizer, Roche, M. Cidon: None declared, A. Ramanan: None declared, Y. Kimura Grant/research support from: Novartis, SOBI, CARRA, Inc (salary support), P. Quartier Grant/research support from: Abbvie, Novartis, Pfizer, Chugai-Roche, Consultant for: Abbvie, Novartis, Pfizer, Roche, Sobi, Speakers bureau: Abbvie, Novartis, Sobi, Roche, I. Foeldvari Speakers bureau: Novartis, Abbvie, Chugai, A. Zeft Shareholder of: Merck, OPKO, ARNI, K. Lomax Employee of: Novartis Pharmaceuticals Corporation, J. Gregson Employee of: Novartis, A. Tineke: None declared, S. Campbell Consultant for: Novartis, J. Weiss Consultant for: Novartis, N. Marinsek Consultant for: Novartis, D. Patel Consultant for: Novartis, N. Wulffraat Grant/research support from: AbbVie, Roche, Sobi, Consultant for: Novartis, Pfizer, Sobi

DOI: 10.1136/annrheumdis-2017-eular.3347

\section{THU0642 THERE IS A COMMUNICATION PROBLEM BETWEEN PATIENT AND PHYSICIAN DURING PRE-CONCEPTIONAL PERIOD: HUR-BIO REAL LIFE RESULTS}

O.A. Uyaroglu ${ }^{1}$, E. Seyhoglu ${ }^{1}$, A. Erden ${ }^{2}$, L. Kılıç ${ }^{2}$, B. Armagan ${ }^{2}$, A. Sarı ${ }^{2}$ Ö. Karadağ ${ }^{2}$, A. Akdoğan ${ }^{2}$, S. Apras Bilgen ${ }^{2}$, S. Kiraz ${ }^{2}$, I. Ertenli ${ }^{2}$ U. Kalyoncu ${ }^{2}{ }^{1}$ Internal Medicine; ${ }^{2}$ Division of Rheumatology, Hacettepe University School of Medicine, Ankara, Turkey

Background: A significant part of patients with inflammatory arthritis are at their reproductive ages. Biological drugs are one of the important treatment options for inflammatory artritis which can cause fetal morbidity and mortality. Management of arthritis during pre-conceptional period is one of the challenges in rheumatology. Objectives: This study aims to assess whether patients under biological treatment share their conception intents with their physicians.
Methods: 1580 patients admitted to our outpatient clinic between July 2015 and July 2016 who were received biological treatment. A questionnaire was performed to 373 patients who are at their reproductive ages. Patients were asked whether they or their wifes had got pregnant after the start of biological agent. If they had got, they were asked;

1. Was the pregnancy intented?

2. Did your physician know if you were going to get pregnant while taking a biological agent?

Results: There were total of 79 patients who or whose wifes had got pregnant after the start of biological agent. $34(\% 43)$ out of 79 were female and $45(\% 57)$ out of were male. Mean age of patients were 35.1 (5.3). Median disease duration was $10($ IQR $=9)$ years. $24(30.4 \%)$ pregnancies out of 79 were not planned [15 female $(44.1 \%)$, 9 male $(20 \%), p=0.021]$. In addition, $43(54.4 \%)$ out of 79 patients did not share their pregnancy plans with their physicians [15 $(44,1 \%)$ female and $28(62,2 \%)$ male $(p=0.110)] .28(35.4 \%)$ of all patients stated that their disease was active during pre-conceptional period $[20(58,8 \%)$ female patients, $8(17,8 \%)$ male patients, $(p<0,001)$ ]

Conclusions: In our study group, almost one third of the patients had unplanned pregnancies particularly with in female patients. One third of the patients were in active state before conception according to patients' report. Almost half of the patients did not share their plan of pregnancy with their physicians. We suggest that in routine practise, physicians should ask plan of pregnancy in every clinical visit.

Disclosure of Interest: None declared

DOI: 10.1136/annrheumdis-2017-eular.4101

\section{THU0643 WHAT FACTORS RELATE TO PATIENTS CONTRIBUTING LONGITUDINAL DATA USING SMARTPHONE TECHNOLOGY? FINDINGS FROM RA PATIENTS PARTICIPATING IN ARTHRITISPOWER REGISTRY}

W.B. Nowell ${ }^{1}$, H. Yun ${ }^{2}$, J. Willig ${ }^{3}$, J. Beaumont ${ }^{4}$, B. Johnson ${ }^{3}$, S. Ginsberg ${ }^{5}$, C. Wiedmeyer ${ }^{5}$, R. Crow-Hercher ${ }^{5}$, B.J. Johnson ${ }^{5}$, S. Yang ${ }^{3}$, J.R. Curtis ${ }^{3}$. ${ }^{1}$ Global Healthy Living Foundation, Upper Nyack; ${ }^{2}$ University of Alabama at Birmingham School of Public Health; ${ }^{3}$ University of Alabama at Birmingham Birmingham; ${ }^{4}$ Northwestern University Feinberg School of Medicine, Evanston; ${ }^{5}$ CreakyJoints, Global Healthy Living Foundation, Upper Nyack, United States

Background: Data capture of patient reported outcomes (PROs) is gradually shifting from data collection on paper in medical office settings to use of computer or mobile based technologies between doctor visits. Concerns have been raised that patients may have limited interest in contributing data over time or that they may only record new data when there has been a change in their clinical status. Objectives: The objective of this study was to evaluate the patterns and factors associated with longitudinal PRO data capture among participants in the PCORIfunded Patient Powered Research Network for adult rheumatologic conditions, ArthritisPower.

Methods: Patients in the registry were asked to voluntarily complete PROs including the RAPID3 and 4 PROMIS instruments plus disease-specific information via a mobile application (App) on their smartphone or computer. We evaluated the average time it took the patient to record each of the instruments and the total number of unique days that patients recorded PROs on the smartphone. Given the newness of the registry (launched late 2015), longitudinal data was defined as contributing at least 2 sets of PROs on unique calendar days. We tested the hypothesis that patients would contribute longitudinal data only when at least one of their scores exceeded a minimally important difference (MID) of any of the 5 PROs examined (generally 2-3 units for PROMIS instruments; 3.6 units for RAPID3). Demographic factors associated with multiple PRO reports were identified using logistic regression among patients who had been enrolled in the registry for at least 3 months.

Results: At the time of analysis, ArthritisPower had recruited 2,103 patients, most (approximately $68 \%$ ) had RA, and $20 \%$ provided their Twitter handle. Average (SD) age was 50 (12); $87 \%$ were women. The mean assessment time for each of the PROMIS instruments ranged from a low of 16 seconds (Sleep Disturbance) to a high of 105 seconds (RAPID3). The average score for Pain Interference was 64.3 (SD: 6.3), Physical Function 37.5 (6.5), Sleep Disturbance 59.3 (8.4), Fatigue 64.2 (8.4), and RAPID3 15.7 (5.3). Of 1.946 patients who registered the Smartphone App more than 3 months prior to analysis, $20.6 \%$ never contributed any PRO information, $53.3 \%$ answered once, and $26.1 \%$ answered at least twice. Among patients with longitudinal data ( $>2$ assessments), the mean change score of PROs between pairwise PRO assessments was $<1$ point for all instruments

Table: Mean change between $1^{\text {tt }}$ and $2^{\text {sed }}$ visit among Arthritispower patients with longitudinal data

\begin{tabular}{|c|c|c|c|}
\hline & $\begin{array}{l}\text { Mean change from } 1^{a x} \text { to } \\
2^{n \infty} \text { visit }\end{array}$ & $\begin{array}{l}\text { Absolute mean change } \\
\text { from } 1^{n \text { In }} \text { to } 2^{\text {nd }} \text { visit }\end{array}$ & $\begin{array}{l}\text { \% of patients exceeding } \\
\text { change }>M I D\end{array}$ \\
\hline PROMIS Physical Function & $-0.4(3.8)$ & $2.7(2.7)$ & $34.2 \%$ \\
\hline PROMIS Pain Interference & $-0.4(5.4)$ & $3.9(3.6)$ & $52.3 \%$ \\
\hline PROMIS Sleep Disturbance & $0.2(6.1)$ & $4.6(4.0)$ & $56 \%$ \\
\hline PROMIS Fatigue & $-0.03(6.6)$ & $4.8(4.4)$ & $55.6 \%$ \\
\hline RAPID3 & $0.2(3.8)$ & $2.8(2.6)$ & $29.8 \%$ \\
\hline
\end{tabular}


(Table). Only $23.1 \%$ of patients contributing longitudinal data had a change greater than the MID in any of the 5 PRO measures. Patients with RA (OR: $1.54,95 \% \mathrm{Cl}$ : $1.14-2.06)$, biologic use $(2.12,1.43-3.15)$, and those with Twitter accounts $(1.40$, 1.08-1.82) were more likely to contribute longitudinal PRO data in the absense of regular reminders.

Conclusions: Multiple factors were associated with patients contributing longitudinal PRO data. Patients were willing to contribute longitudinal PRO data even in the absence of a change in their health state exceeding any MID. Additional efforts are needed to engage patients to contribute PRO data over time.

Disclosure of Interest: None declared

DOI: 10.1136/annrheumdis-2017-eular.5370

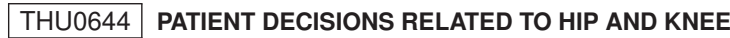 ARTHROPLASTY AND THE FACTORS INFLUENCING THEM}

W.B. Nowell ${ }^{1}$, S. Venkatachalam ${ }^{2}$, E. Harden ${ }^{2}$, T. Concannon ${ }^{3,4,5},{ }^{1}$ Global Healthy Living Foundation, Upper Nyack, United States; ${ }^{2}$ CreakyJoints, Global Healthy Living Foundation, Upper Nyack; ${ }^{3}$ Tufts Clinical and Translational Science Institute; ${ }^{4}$ Tufts University School of Medicine; ${ }^{5}$ The RAND Corporation, Boston, United States

Background: Patient-engaged research can improve the safety and satisfaction outcomes of hip and knee arthroplasty (joint replacement surgery).

Objectives: The objective of this study was to identify the decisions that are most important to patients when undergoing hip or knee arthroplasty and the factors they view as important in making those decisions.

Methods: Forty-nine U.S. participants were recruited from ArthritisPower PatientPowered Research Network and CreakyJoints arthritis patient community to participate in structured one-hour discussions held via webinar during January to April 2016 to understand patients' experiences with joint replacement. Patients described decisions that were most important to them and the factors they used to make those decisions. Discussions were transcribed and coded to identify themes; patient decisions and factors were identified and categorized and co-occurrence of decisions and factors was tabulated. Demographic and procedure-related characteristics were captured.

Results: Eight decisions emerged that were influenced by at least ten factors (Table). The most important decisions involved whether to have surgery, selection of surgery date, surgeon, facility, implant device, and ancillary health care professionals (HCPs) and services. Factors included current situation, expectations of having or not having surgery, professional and word-of-mouth familiarity with surgeon/HCP, procedure, services and device, and perceived value. Patients' current situation and health status and their expectations of surgery were most commonly used to make decisions about whether and when to have surgery. Patients' trust of and communication with doctors was the most commonly factor used when deciding on arthroplasty surgeon.

\begin{tabular}{|c|c|}
\hline Decisions Important to Patients & Most Common Factors Influencing Decisions \\
\hline $\begin{array}{l}\text { Surgery: Whether to have partial or total hip/knee } \\
\text { joint replacement surgery (arthroplasty) }\end{array}$ & $\begin{array}{l}\text { Current life situation / health status ( } 44 \%) \text {, } \\
\text { Expectations of surgery }(11 \%) \text {, Information provided } \\
\text { to patient by doctor } / \mathrm{HCP}(11 \%) \text {, Alternatives to } \\
\text { surgery (11\%) }\end{array}$ \\
\hline Timing: When to have surgery & $\begin{array}{l}\text { Current life situation and health status ( } 38 \% \text { ), } \\
\text { Expectations of surgery }(19 \%) \text {, Alternatives to surgery } \\
(19 \%)\end{array}$ \\
\hline Surgeon: Which surgeon will perform surgery & $\begin{array}{l}\text { Trust and communication with surgeon ( } 45 \%) \text {, } \\
\text { Perceived value of surgeon's expertise (19\%), } \\
\text { Expectations of surgery (16\%), Information accessed } \\
\text { by patient (10\%) }\end{array}$ \\
\hline $\begin{array}{l}\text { Facility: Where surgery will be performed (e.g., } \\
\text { location, specific hospital or medical center) }\end{array}$ & $\begin{array}{l}\text { Information provided to patient by doctor/HCP (28\%), } \\
\text { Trust and communication with HCP (18\%), Firsthand } \\
\text { familiarity with facility (18\%), Expectations of surgery } \\
\text { (18\%), Information accessed by patient (9\%), } \\
\text { Perceived value of facility expertise (9\%) }\end{array}$ \\
\hline $\begin{array}{l}\text { Device: Which implant device will be installed during } \\
\text { surgery }\end{array}$ & $\begin{array}{l}\text { Expectations of surgery }(39 \%) \text {, Information provided } \\
\text { to patient by doctor } / \mathrm{HCP}(18 \%) \text {, Perceived value of } \\
\text { device }(16 \%) \text {, Trust and communication with HCP } \\
\text { (11\%) }\end{array}$ \\
\hline $\begin{array}{l}\text { Approach: Specific approach to surgery (e.g., anterior } \\
\text { vs. posterior, bilateral joint replacement) }\end{array}$ & $\begin{array}{l}\text { Expectations of surgery ( } 45 \%) \text {, Trust and } \\
\text { communication with surgeon }(42 \%) \text {, firsthand } \\
\text { familiarity with other } \mathrm{HCPS}(18 \%)\end{array}$ \\
\hline $\begin{array}{l}\text { Other HCPs: Who/which other health care } \\
\text { professionals (HCPs) besides the surgeon will be } \\
\text { involved in care during and after surgery }\end{array}$ & $\begin{array}{l}\text { Expectations of surgery (30\%), Trust and } \\
\text { communication with HCP }(20 \%) \text {, Current life situation } \\
\text { / health status }(20 \%) \text {, Perceived value of / familiarity } \\
\text { with other HCPS (20\%) }\end{array}$ \\
\hline $\begin{array}{l}\text { Other Services: What other services will be necessary } \\
\text { before, during or after surgery }\end{array}$ & $\begin{array}{l}\text { Expectations of surgery }(71 \%) \text {, Trust and } \\
\text { communication with HCP }(14 \%) \text {, Current life situation } \\
\text { / health status (14\%) }\end{array}$ \\
\hline
\end{tabular}

Conclusions: Arthroplasty patients are concerned about a variety of decisions. Patient-centered research should maximally address questions of importance to patients and this study is a first step in identifying and prioritizing topics that matter most to patients and the information that patients currently use to make joint replacement decisions.

Acknowledgements: This project was funded through a Patient-Centered Outcomes Research Institute (PCORI) Eugene Washington PCORI Engagement Award (2228-GHLF).

Disclosure of Interest: None declared

DOI: 10.1136/annrheumdis-2017-eular.5291

\section{THU0645 OPTIMIZING THE EFFICIENCY OF PATIENT DATA CAPTURE USING SMARTPHONE TECHNOLOGY: EVALUATION OF THE CORRELATION BETWEEN PROMIS INSTRUMENTS FOR PRO DATA CAPTURE}

W.B. Nowell ${ }^{1}$, H. Yun ${ }^{2}$, J. Beaumont ${ }^{3}$, S. Yang ${ }^{4}$, J. Willig ${ }^{4}$, S. Ginsberg ${ }^{5}$, K.V. Clayton ${ }^{5}$, S. Hazel ${ }^{5}$, C. Wiedmeyer ${ }^{5}$, J.R. Curtis ${ }^{4}{ }^{1}{ }^{1}$ Global Healthy Living Foundation, Upper Nyack; ${ }^{2}$ University of Alabama at Birmingham School of Public Health, Birmingham; ${ }^{3}$ Northwestern University Feinberg School of Medicine, Evanston; ${ }^{4}$ University of Alabama at Birmingham, Birmingham; ${ }^{5}$ CreakyJoints, Global Healthy Living Foundation, Upper Nyack, United States

Background: Patient-reported outcomes (PROs) are key to enabling the comprehensive assessment of patient-centered benefits in comparative effectiveness research (CER). However, the relationships between different PROMIS instruments and condition-specific disease activity measures in diseases such as rheumatoid arthritis (RA) have not been well studied.

Objectives: The objectives of this analysis were to evaluate the longitudinal relationship between different PROMIS instruments and the RAPID3, a measure of self-reported patient disease activity.

Methods: Four NIH PROMIS instruments (Pain Interference, Physical Function, Sleep Disturbance and Fatigue) and the RAPID3 were administered to participants in the PCORI-funded ArthritisPower patient registry. After descriptive analytics, we estimated multiple correlations between PROMIS instruments and the RAPID3. For each PRO instrument and with each assessment used as the unit of measure, we calculated the R-squared using mixed models to evaluate how the PROs were related to each other. Using Pain Interference as an example, we evaluated Rsquared for each model with additional PROs and demographic factors including enrollment age, sex, race, Twitter account, region, and visit times.

Results: A total of 1,590 unique participants who answered the survey one or more times were included in the analysis, with mean (SD) age of 49 (12) years. The mean score for Pain Interference was 63.7 (SD: 7.0), Physical Function 37.5 (8.7), Sleep Disturbance 58.4 (8.7), Fatigue 63.8 (8.8), and RAPID3 15.5 (5.7). Most PROMIS instruments were low to moderately correlated (around $0.2)$ with each other and the RAPID3. Using Pain Interference as an example, $R$-squared measures revealed a high total variance explained $\left(R^{2}=49 \%\right)$ between Pain Interference and Physical Function (Table); those involving Pain Interference, Physical Function, Fatigue, Sleep Disturbance and RAPID3 also revealed a higher variance contribution with these additional PROs (66\%). Additional adjustment for demographic factors added little variance explanation (1.4\%).

Table: Total variance explained by predictors (R-Squared) with PROMIS Pain Interference as the dependent variable

\begin{tabular}{|l|r|r|}
\hline $\begin{array}{l}\text { Models with PROMIS Pain Interference } \\
\text { as the dependent variable }\end{array}$ & \multicolumn{1}{|c|}{$\begin{array}{c}\text { Pain variance that } \\
\text { could not be } \\
\text { explained by } \\
\text { predictors }\end{array}$} & $\begin{array}{l}\text { Total variance that } \\
\text { could be explained } \\
\text { by predictors } \\
\text { (R-Squared) }\end{array}$ \\
\hline $\begin{array}{l}\text { Baseline model: } \\
\text { no predictors }\end{array}$ & 42.6 & \\
\hline $\begin{array}{l}\text { Model with predictors: } \\
\text { PROMIS Physical Function }\end{array}$ & 22.6 & \\
\hline $\begin{array}{l}\text { Model with predictors: } \\
\text { PROMIS Physical Function, Sleep Disturbance }\end{array}$ & 20.7 & \\
\hline $\begin{array}{l}\text { Model with predictors: } \\
\text { PROMIS Physical Function, Sleep Disturbance, } \\
\text { Fatigue }\end{array}$ & & $51.6 \%$ \\
\hline $\begin{array}{l}\text { Model with predictors: } \\
\text { PROMIS Physical Function, Sleep Disturbance, } \\
\text { Fatigue, RAPID3 }\end{array}$ & 18.7 & \\
\hline $\begin{array}{l}\text { Model with predictors: } \\
\text { PROMIS Physical Function, Sleep Disturbance, } \\
\text { Fatigue, RAPID3 and demographic predictors } \\
\text { (age, gender, race, region, etc.) }\end{array}$ & 15.3 & $56.1 \%$ \\
\hline $\begin{array}{l}\text { Model with only demographic predictors: } \\
\text { age, gender, race, region, etc. }\end{array}$ & & \\
\hline
\end{tabular}

Conclusions: PROMIS Pain Interference, Physical Function, Sleep Disturbance, Fatigue instruments and RAPID3 are reasonably correlated to each other. Age, gender, race and other demographic factors play little role in explaining variance in PROs. These results suggest potential efficiencies in using some measures to predict or impute the values for other measures and to optimize the frequency of patient data collection using at-home technologies including Smartphone Apps like ArthritisPower.

Disclosure of Interest: None declared

DOI: 10.1136/annrheumdis-2017-eular.5329 